\title{
The effect of a low molecular weight inhibitor of lipid peroxidation on ultrastructural alterations to ischemia-reperfusion in the isolated rat heart
}

\author{
A. Nagy ${ }^{1}$, R. Myklebust ${ }^{2}$, G. Valen ${ }^{1}$, P.-O. Sjöquist ${ }^{3}$, J. Vaage $^{4}$ \\ ${ }^{1}$ Crafoord Laboratory, Karolinska Institutet, Stockholm, Sweden \\ ${ }^{2}$ Department of Morphology, Institute of Medical Biology, University of Troms $\varnothing$, Norway \\ ${ }^{3}$ AstraZeneca R \& D, Mölndal, Sweden \\ ${ }^{4}$ Department of Thoracic Surgery, Karolinska Hospital, Stockholm, Sweden
}

Received: June 29, 2001

Accepted: September 3, 2001

\begin{abstract}
The effects of H290/51, a novel indenoindole derivative inhibitor of lipid peroxidation, on ultrastructural changes during cardiac ischemia-reperfusion injury were investigated. Langendorff-perfused rat hearts were exposed to 30 minutes of global ischemia followed by 20 minutes of reperfusion: Group A: Control hearts with standard buffer perfusion with vehicle added. Group B: H290/51 $\left(10^{-6} \mathrm{~mol} / \mathrm{l}\right)$ added to buffer throughout stabilisation and reperfusion. In an additional Group C, where hearts were given H290/51, but not subjected to ischemia, the ultrastructure was preserved till the end of reperfusion. Absolute volumes and calculated volume fractions ( $\mathrm{Vv}$ ) of tissue and subcellular components were assessed with quantitative stereologic morphometry. After ischemia the increase in volume of extracellular interstitium was inhibited by $\mathrm{H} 290 / 51$ (247 \pm 80 vs. $159 \pm 50 \mu \mathrm{l}$, mean $\pm \mathrm{SD}$, groups $\mathrm{A}$ and $\mathrm{B}$, respectively, $\mathrm{p}<0.05)$. The $\mathrm{Vv}$ (interstitium/myocard) was higher in control hearts $(0.318 \pm 0.062$ vs. $0.206 \pm 0.067, \mathrm{p}<0.05)$. $\mathrm{Vv}$ (cell edema/myocyte) was higher in the control group $(0.144 \pm 0.07$ vs. $0.083 \pm 0.033, \mathrm{p}<0.05)$. Vv (myocyte/myocard) was higher in group B after ischemia than in the control group (0.622 \pm 0.071 vs. $0.707 \pm 0.052, \mathrm{p}<0.05$ ). The decreased $\mathrm{Vv}$ (capillary/myocard) after ischemia was inhibited by $\mathrm{H} 290 / 51$. After reperfusion there was no difference between groups. Treatment with H290/51 reduced edema and ensured better preserved sarcolemmal membrane structure during ischemia. The effect was no longer present after reperfusion.
\end{abstract}

Correspondence should be addressed to

András Nagy

County Hospital, Department of Medicine (Cardiology)

H-6000 Kecskemét, Nyíri út 38, Hungary

Phone: (76) 516-700

Fax: (76) 488-770

E-mail:nagya@kmk.hu 
Keywords: free radicals, ischemia - reperfusion, ultrastructure, rat, lipid peroxidation, Langendorff-perfused rat heart

Although reperfusion is a prerequisite for survival of an ischemic myocardium, it may also exacerbate the injury sustained during ischemia $(2,12)$. Although a variety of mechanisms and mediators are involved in the development of ischemia-reperfusion injury, substantial evidence indicates a major role of reactive oxygen species (ROS) (7, 17, 27). Production of ROS during ischemia and reperfusion has been measured in vivo by electron paramagnetic resonance spectroscopy (37). Lipid peroxidation is suggested to be a main mechanism of ROS mediated injury of cell membranes and intracellular organelles (23). In the myocardium the highest level of ROS formation was detected in the mitochondria and the sarcolemma $(3,25)$.

Vitamin E may be the most important endogenous antioxidant, however, its lipophilicity causes slow tissue incorporation, thus rendering it less feasible for treatment in acute situations. A novel indenoindole derivative, H290/51 (cis5,5a,6,10,b-tetrahydro-9-methoxy-7-methylindeno (2,1-b)indole) has been investigated in different settings of experimental ischemia-reperfusion $(21,22,29,32,33)$. The lipophilicity of H290/51 is considerably lower than that of vitamin E. As H290/51 is a small molecule (molecular weight: 287.8) with balanced hydro- and lipophilicity, it can rapidly penetrate cell membranes to intracellular sites of ROS generation, lipid peroxidation, and oxidant injury. Thus, in contrast to most other antioxidants H290/51 may effectively give protection to jeopardized subcellular compartments.

We have previously reported that H290/51 attenuated lipid peroxidation, and biochemical and functional injury in isolated rat hearts perfused with hydrogen peroxide (21) or exposed to global ischemia-reperfusion (22). It also prevented reoxygenation injury in cultured myocytes (22). The aim of the present study was to assess the effect of inhibiting lipid peroxidation by $\mathrm{H} 290 / 51$ on ultrastructural changes in isolated rat hearts subjected to ischemia and reperfusion. Random sampling and stereological techniques were employed to ensure an objective, quantitative evaluation.

\section{Materials and Methods}

\section{Experimental procedure}

The experiments were approved by the Regional Ethics Committee at the Karolinska Institute. All animals received care in compliance with the Guide for the Care and Use of Laboratory Animals published by the National Institutes of Health. Male Sprague-Dawley rats, weighing 250-300 g, were anesthetized with diethyl ether. Heparin (200 IU) was injected into the femoral vein. The hearts were rapidly excised through a median sternotomy and immediately immersed into ice-cold Krebs-Henseleit buffer during preparation. The ascending aorta was cannulated for retrograde perfusion 
as a modified Langendorff preparation. Perfusion pressure $\left(100 \mathrm{~cm} \mathrm{H}_{2} \mathrm{O}\right)$ and temperature $\left(37^{\circ} \mathrm{C}\right)$ were kept constant. The hearts were perfused with Krebs-Henseleit buffer containing glucose $\left(\mathrm{NaCl} 118.5 \mathrm{mM}, \mathrm{NaHCO}_{3} 25.0 \mathrm{mM}, \mathrm{KCl} 4.7 \mathrm{mM}, \mathrm{KH}_{2} \mathrm{PO}_{4}\right.$ $1.2 \mathrm{mM}, \mathrm{MgSO}_{4} \times 7 \mathrm{H}_{2} \mathrm{O} 1.2 \mathrm{mM}, \mathrm{CaCl}_{2} 2.4 \mathrm{mM}$, Glucose $\left.\times \mathrm{H}_{2} \mathrm{O} 11.1 \mathrm{mM}\right)$ and bubbled with a gas mixture containing $95 \% \mathrm{O}_{2}$ and $5 \% \mathrm{CO}_{2}$. Coronary flow $(\mathrm{CF})$ was measured by collecting the coronary effluent every 2.5 min to adjust drug infusion to changes in flow. Hemodynamic measurements were not carried out in order to avoid the possibility of secondary subendocardial morphology changes due to tension of an inserted balloon $(21,22)$.

The perfusion protocol started with a 25 -minutes stabilisation period, after which all functional parameters were stable $(21,22)$. Only hearts where CF was between 7 and $15 \mathrm{ml} / \mathrm{min}$ were included. Global, normothermic ischemia was induced by clamping the inflow tubing for 30 minutes, followed by 20 minutes of reperfusion.

The following groups were investigated: Group A: control hearts perfused with buffer and vehicle subjected to ischemia and reperfusion as described above. Hearts were sampled for preparation for electron microscopy at the end of stabilisation (time 0 ), at the end of ischemia (30 minutes) and at the end of reperfusion (50 minutes; $n=6$ at each point of time in each group). Group B: like Group A, but with H290/51 added throughout both stabilisation and reperfusion. Hearts were sampled as in Group A. In an additional Group C hearts were not subjected to ischemia, but H290/51 was added throughout the experiment. Hearts in this group were only sampled for morphometric evaluation at $50 \mathrm{~min}(\mathrm{n}=6)$.

\section{Chemicals}

H290/51 (AstraZeneca R \& D, Mölndal, Sweden) was dissolved in a vehicle containing polyethylene glycol, ethanol and water in a 40:10:50 w/w percentage ratio. H290/51 or vehicle alone was administered with an infusion pump at a rate of 1/20th of coronary flow into a mixing chamber immediately upstream to the aortic cannula, to obtain a concentration of $10^{-6} \mathrm{~mol} / \mathrm{l}$ in the coronary circulation. This concentration was selected according to previous in vitro studies where dose-dependent inhibition of lipid peroxidation was observed, with maximal effects at $10^{-6} \mathrm{M}(22)$.

\section{Preparation for electron microscopy}

At the end of experiments hearts were perfusion fixed with McDowel's fixative for $10 \mathrm{~min}$ at room temperature and at a perfusion pressure of $60 \mathrm{~cm} \mathrm{H}_{2} \mathrm{O}$ (20). Only the ventricular myocardium was used for morphometric measurements. After cutting away the atria from the ventricles, the volume of the ventricular myocardium was read by immersing the pieces into a glass container scaled for volume measurements filled with phosphate buffer. The measurement of volume, obtained by liquid displacement, was repeated three times for each ventricle, and the average volume expressed in $\mu$ l was used for further calculations. The hearts were then kept in fixative. At the final 
processing the ventricles were cut into 1 and $2 \mathrm{~mm}$ thick parallel slices with a razor blade apparatus as described by the International Society for Stereology (4). All the $1 \mathrm{~mm}$ thick slices were then placed at random under a regularly perforated plexiglass plate. The perforations were placed in a square $(32 \mathrm{~mm} \times 32 \mathrm{~mm})$ and separated from each other by a distance of $2 \mathrm{~mm}$. Each perforation had a diameter of $1 \mathrm{~mm}$. Using a biopsy needle, one biopsy was taken at every second perforation. After wash in phosphate buffer the biopsies were postfixed in $1 \%$ aqueous $\mathrm{OsO}_{4}$ for 2 hours. After a subsequent wash in buffer the pieces were stained in $2 \%$ uranyl sulphate for $1.5 \mathrm{~h}$. The pieces were dehydrated in a series of graded alcohol before embedding in a mixture of Epon and Araldite. Eight pieces of ventricular biopsies were taken from each animal, and out of this, five samples were selected randomly for further stereologic processing. Thin sections were placed on cupper grids and stained with Reynolds lead citrate for $8 \mathrm{~min}$, and subsequently with 5\% uranyl acetate for $5 \mathrm{~min}$. A systematic randomised procedure was used to select fields to be photographed. The upper left corner of the copper grid squares was used as a reference point when selecting fields to be photographed, and every second field was photographed totalling 5 fields per sample. All micrographs were taken at a final magnification of $\times 10000$. A total of 25 micrographs per heart were the basis of quantitative evaluation.

\section{Stereology}

Volume fractions were estimated using the point counting method described by Weibel and Bolender (31). In short, a counting grid with sampling points was laid on the micrographs and points overlying different tissue and cell components were counted and related to points falling on a reference unit (that is, the whole myocardium on a micrograph). The counting was performed on coded specimens. Volumes of mitochondria, altered mitochondria and cellular edema were estimated as fractions of myocyte volume and denoted: $V_{v}$ (mito/myocyte), $V_{v}$ (alt mito/myocyte), $V_{v}$ (cell edema/myocyte). Volume fractions of myocytes, interstitium and capillaries in total myocardium were estimated: $V_{v}$ (myocyte/myocard), $V_{v}$ (interstitium/myocard), $V_{v}$ (capillary/myocard). The absolute volume of different tissue components was calculated by multiplying the volume fraction of the tissue component with the respective measured ventricular volume as described above and given as $\mu$. In addition, the planar sections of cells appearing on micrographs from different groups were inspected. A semiquantitative evaluation was undertaken. Altered mitochondria were defined as rounded mitochondria with reduced contrast (loss of matrix density). More pronounced changes in mitochondria were also counted as altered mitochondria. Cellular edema was defined as clear spaces in cytosol of the myocytes. 


\section{Statistical analysis}

The Mann-Whitney test and the Wilcoxon Signed Rank Test were used to analyse differences between and within groups, respectively. $p<0.05$ was considered significant. All values presented are means \pm SD.

\section{Results}

\section{Ultrastructural changes in the myocardium}

The myocardium before ischemia is shown in Figure 1. Myocytes with mitochondria and other cell organelles appear normal as do the endothelial cells.

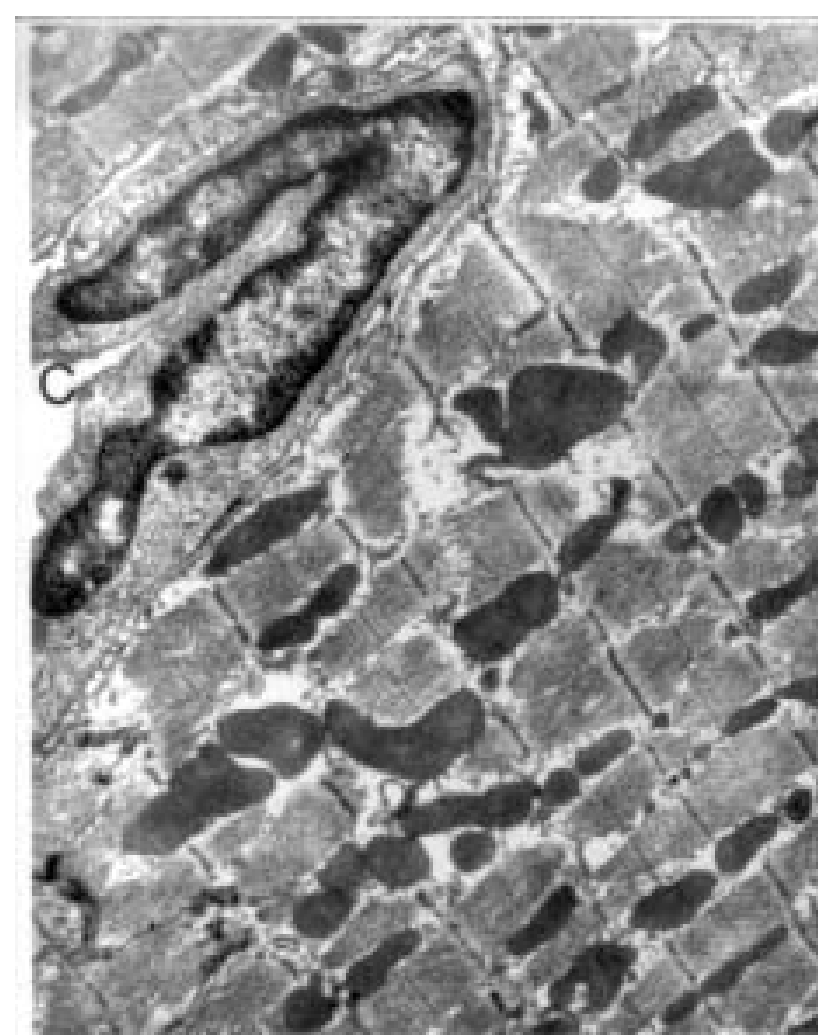

Fig. 1. Electron micrograph of rat myocardium before ischemia. The structure of myocytes appears normal. An endothelial cell of a capillary (C) is also shown with finely dispersed nuclear chromatin. $\times 10000$ 


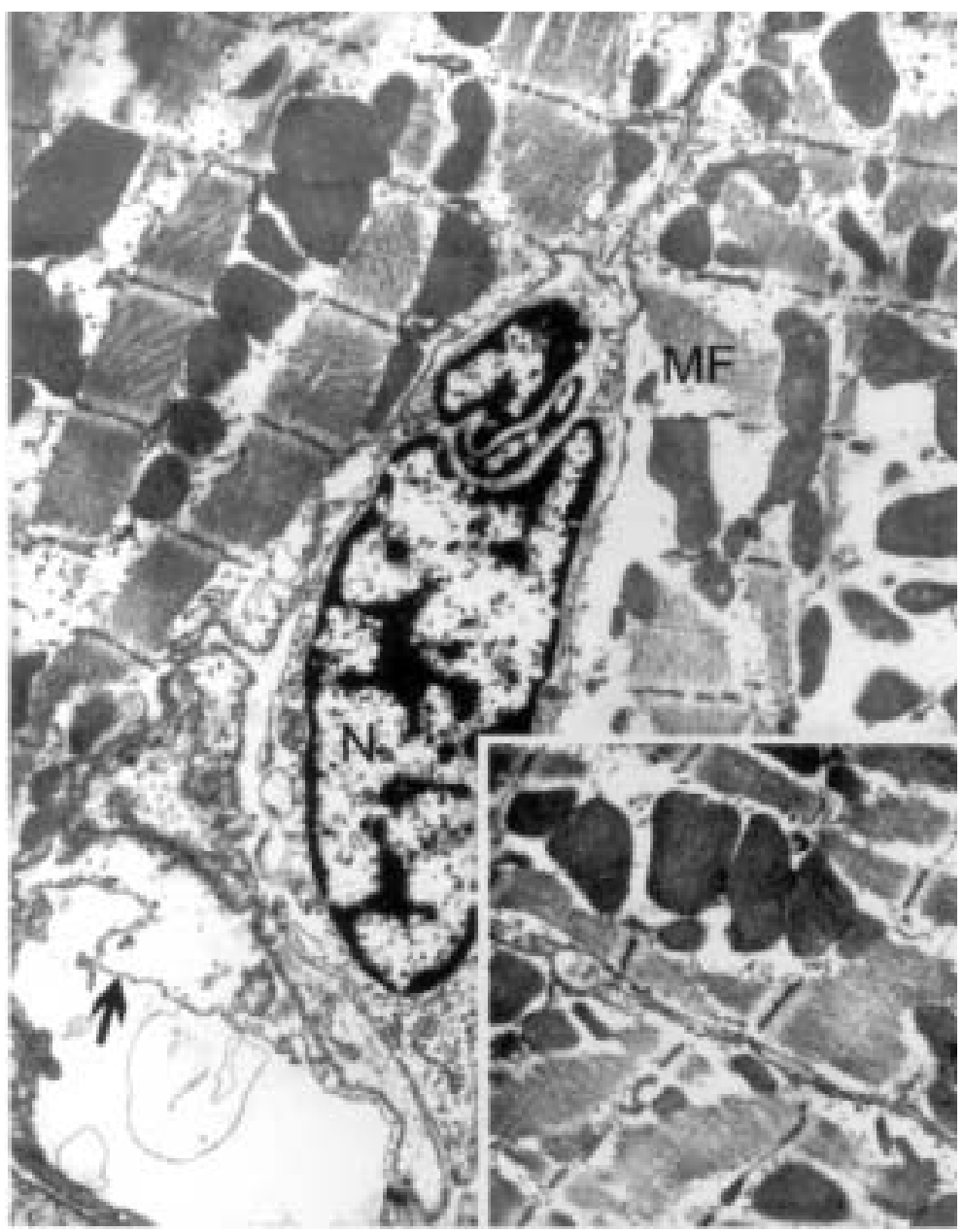

Fig. 2. Two myocytes are shown on the micrograph sampled from control group (Group A) after $30 \mathrm{~min}$ ischemia. One of them reveals a moderate intracellular edema with moderate mitochondrial swelling and intact sarcolemma. The other is damaged, edematous, the myofilamental pattern (MF) is disrupted. The cytoplasm of the endothelial cell is edematously swollen with luminal protrusions (arrow). Chromatin margination of the nucleus $(\mathrm{N})$ is observed. The inserted micrograph shows a fairly well-maintained structure, apart from fragmentation of the sarcolemma. $\times 10000$

In control hearts perfused with H290/51 throughout perfusion (Group C), the ultrastructural components appeared normal at the end of perfusion. The results of Group $\mathrm{C}$ are not further commented.

After ischemia areas with damaged cells were observed on most micrographs. In control hearts (Group A) myocytes were swollen with perimitochondrial and 
perimyo-fibrillar edema (Fig. 2). In severely damaged myocytes the sarcolemma was fragmented. Subsarcolemmal blebs occurred in more severely injured myocytes with massive cell swelling. The myofilamental pattern became irregular and $\mathrm{Z}$ lines were distorted. In more severely injured myocytes myofilaments were disrupted with a loss of $\mathrm{Z}$ lines. Mitochondria generally appeared swollen and rounded. The mitochondrial matrix showed loss of electron density. Occasionally mitochondrial cristae were broken or amorphous matrix densities appeared showing severe damage. Cristal adhesions were found in severely altered mitochondria. There was also evidence of tissue edema and endothelial cells showed swelling with luminal protrusions. Cellular debris accumulated where severe damage was evident. Thirty minutes of ischemia also caused margination of nuclear chromatin in both endothelial and myocardial cells. On micrographs sampled from hearts treated with H290/51 (Group B) the ischemic damage was less apparent, the structure remained fairly normal (Fig. 3). In most myocytes myofilamental pattern was better preserved and edematous changes were less marked both intracellularly and interstitially. However, foci of damaged myocytes were observed.

Most ischemic changes persisted after reperfusion. There were no signs of progressive damage during reperfusion. Interstitial edema tended to increase in the control group. Within the myocytes the fluid accumulation seen after ischemia decreased during reperfusion. Myofilamental pattern was restored on many micrographs (Fig. 4).

\section{Morphometry}

\section{Absolute volume of ventricular myocardium and different tissue components}

Table I summarises absolute volumes of ventricular myocardium and tissue components. There was no significant change in the volume of ventricular myocardium, myocytes, myofilaments, mitochondria or capillaries after 30 minutes of global ischemia in either group. However, the cytosolic volume was significantly increased in both groups after ischemia and returned to baseline after 20 minutes of reperfusion. The extracellular interstitium increased in the control group compared to baseline at the end of ischemia. Treatment with H290/51 inhibited this increase (Table I). At the end of reperfusion the interstitium of both groups had increased compared to baseline (Table I), but there was no difference between the two groups. In addition to the increases of the volume of the interstitium both the ventricular volume and the volume of mitochondria had increased after reperfusion in control hearts, but not in the H290/51 treated group. This difference was not significant between groups (Table I). 


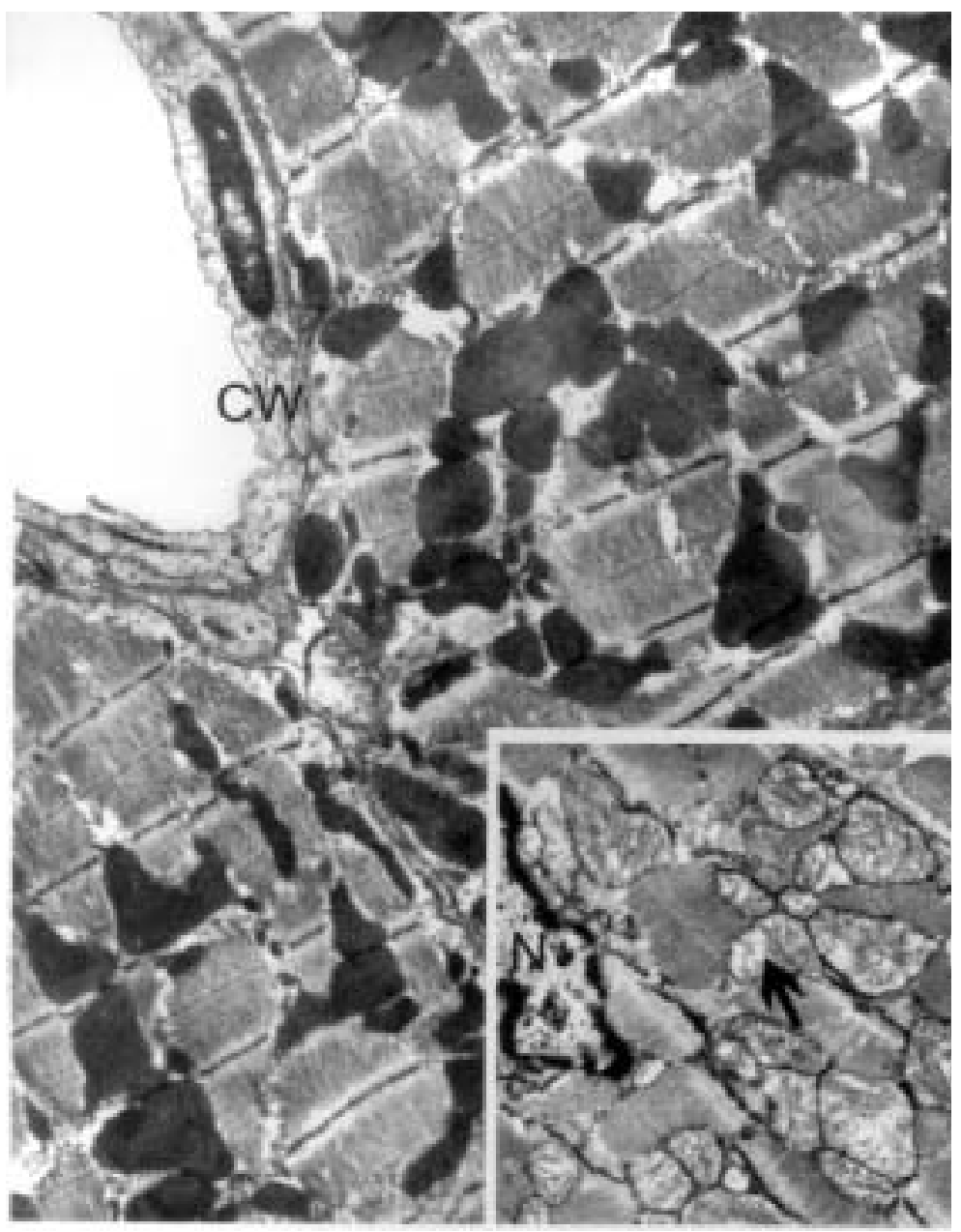

Fig. 3. Electron micrograph taken of rat heart treated with H290/51 exposed to 30 min ischemia. The structure is fairly well-maintained, apart from a mild intracellular edema. The capillary wall (CW) reveals a normal structure, the chromatin is finely dispersed in the nucleus of the endothelial cell. On the insert the myocardium is damaged. The mitochondrial cristae are disrupted (arrow). The remnants of myofilaments are only partly preserved. The nuclear chromatin margination is conspicuous $(\mathrm{N}) . \times 10000$ 


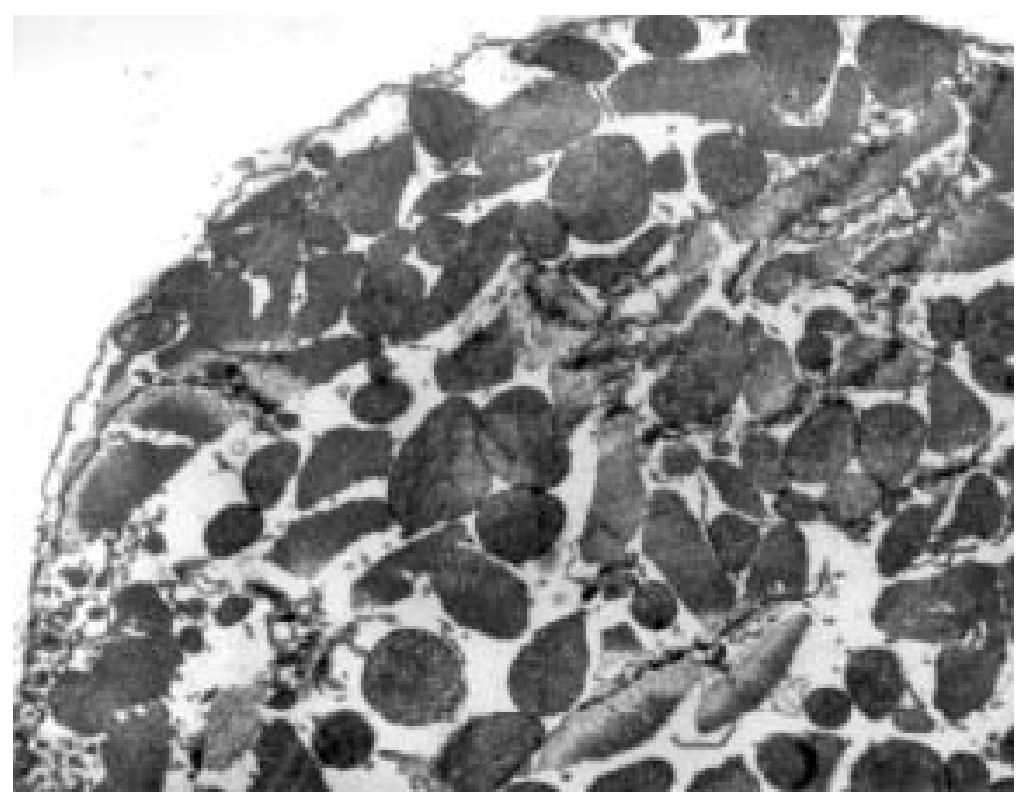

Fig. 4. Cross-section of the myocytes are seen on the micrograph taken after 20 min reperfusion in the group treated with H290/51. There is moderate intracellular edema. The damages of the myofilaments and the mitochondrial cristae are moderate. $\times 10000$

Table I

Effects of 30 minutes of ischemia followed by 20 minutes of reperfusion on absolute volumes $(\mu l)$ of ventricular myocardium and different tissue components in isolated, perfused rat hearts (controls $=$ group $A$ and hearts treated with $H 290 / 51=$ group $B)(n=6$ in each group at each time point $)$

\begin{tabular}{llcrr}
\hline & & 0 min & $\begin{array}{c}30 \text { min } \\
\text { end of ischemia }\end{array}$ & $\begin{array}{c}50 \text { min } \\
\text { end of reperfusion }\end{array}$ \\
\hline Ventricular volume & Group A & $663 \pm 92$ & $768 \pm 104$ & $955 \pm 84^{*}$ \\
& Group B & $775 \pm 87$ & $782 \pm 94$ & $922 \pm 146$ \\
Myocyte & Group A & $430 \pm 81$ & $473 \pm 43$ & $532 \pm 69$ \\
& Group B & $460 \pm 80$ & $554 \pm 90$ & $472 \pm 139$ \\
Myofil & Group A & $266 \pm 65$ & $219 \pm 40$ & $295 \pm 63$ \\
& Group B & $271 \pm 36$ & $286 \pm 57$ & $253 \pm 94$ \\
Mitochondria (total) & Group A & $142 \pm 22$ & $179 \pm 27$ & $204 \pm 30^{*}$ \\
& Group B & $161 \pm 36$ & $206 \pm 48$ & $181 \pm 55$ \\
Cytosol & Group A & $19 \pm 10$ & $68 \pm 33^{*}$ & $23 \pm 15$ \\
& Group B & $14 \pm 4$ & $47 \pm 21^{*}$ & $24 \pm 15$ \\
Interstitium & Group A & $177 \pm 47$ & $247 \pm 80^{*} \#$ & $342 \pm 109^{*}$ \\
& Group B & $232 \pm 31$ & $159 \pm 50$ & $389 \pm 64^{*}$ \\
Capillaries & Group A & $62 \pm 20$ & $47 \pm 20$ & $80 \pm 38$ \\
& Group B & $82 \pm 35$ & $68 \pm 17$ & $61 \pm 24$ \\
\hline
\end{tabular}

$*$ denotes $\mathrm{p}<0.05$ compared to baseline value. \# denotes $\mathrm{p}<0.05$ between groups 
Volume fractions of different tissue components in the myocardium

Relative volumes of tissue components calculated as volume fractions $\left(V_{v}\right)$ of the myocardium are presented in Table II. The volume fraction of myocytes increased after ischemia in the treated group, and at this point of time it was also higher than in the control group. During reperfusion it decreased in both groups without any difference between groups (Table II). Ischemia increased the volume fraction of the interstitium in control hearts compared to baseline. This increase was inhibited in the group given $\mathrm{H} 290 / 51$, but during reperfusion the volume fraction of the interstitium increased in the treated group (Table II). The decreased volume fraction of capillaries in the myocardium after ischemia was inhibited by H290/51 (Table II).

\section{Volume fractions of subcellular components versus myocytes}

All data are presented in Table III. Volume fractions of mitochondria increased in control hearts at the end of ischemia and remained high during reperfusion. This increase was prevented by $\mathrm{H} 290 / 51$, but there was no difference between groups.

\section{Table II}

Effects of 30 minutes of ischemia followed by 20 minutes of reperfusion on the calculated volume fractions of different tissue components in isolated, perfused rat hearts (controls $=$ group A and hearts treated with $H 290 / 51=$ group B) $(n=6$ in each group at each time point $)$

\begin{tabular}{lcccc}
\hline & & $0 \mathrm{~min}$ & $\begin{array}{c}30 \mathrm{~min} \\
\text { end ischemia }\end{array}$ & $\begin{array}{c}50 \text { min } \\
\text { end of reperfusion }\end{array}$ \\
\hline Vv (myocyte/myocard) & & & & \\
& Group A & $0.645 \pm 0.060$ & $0.622 \pm 0.071$ & $0.562 \pm 0.090$ \\
& Group B & $0.591 \pm 0.036$ & $0.707 \pm 0.052 * \#$ & $0.505 \pm 0.079$ \\
Vv (interstitium/myocard) & Group A & $0.355 \pm 0.060$ & $0.318 \pm 0.062 \#$ & $0.356 \pm 0.105$ \\
& Group B & $0.305 \pm 0.064$ & $0.206 \pm 0.067$ & $0.431 \pm 0.093$ \\
Vv (capillary/myocard) & Group A & $0.091 \pm 0.022$ & $0.059 \pm 0.019 * \#$ & $0.083 \pm 0.038$ \\
& Group B & $0.104 \pm 0.034$ & $0.087 \pm 0.021$ & $0.065 \pm 0.017$ \\
\hline
\end{tabular}

* denotes $\mathrm{p}<0.05$ compared to baseline value. \# denotes $\mathrm{p}<0.05$ between groups 


\section{Table III}

Effects of 30 minutes of ischemia followed by 20 minutes of reperfusion on the calculated volume fractions of different subcellular organelles in myocytes in isolated, perfused rat hearts (controls $=$ group A and hearts treated with $H 290 / 51=$ group B) ( $n=6$ in each group at each time point)

\begin{tabular}{|c|c|c|c|c|}
\hline & & $0 \mathrm{~min}$ & $\begin{array}{c}30 \mathrm{~min} \\
\text { end of ischemia }\end{array}$ & $\begin{array}{c}50 \mathrm{~min} \\
\text { end of reperfusion }\end{array}$ \\
\hline \multicolumn{5}{|c|}{ Vv (mito/myocyte) } \\
\hline \multirow{2}{*}{$0.049 *$} & Group A & $0.333 \pm 0.023$ & $0.380 \pm 0.052$ & $0.386 \pm$ \\
\hline & Group B & $0.347 \pm 0.021$ & $0.367 \pm 0.040$ & $0.387 \pm 0.064$ \\
\hline \multirow[b]{2}{*}{$0.187^{*}$} & Groun A & $0+0$ & $0307+0094$ & $0158+$ \\
\hline & & $-\infty$ & I. & \\
\hline $0.139 *$ & Group B & $0 \pm 0$ & $0.233 \pm 0.145$ & $0.200 \pm$ \\
\hline \multicolumn{5}{|c|}{ Vv (cell edema/myocyte) } \\
\hline & Group A & $0.047 \pm 0.025$ & $0.144 \pm 0.070$ & $0.044 \pm 0.030$ \\
\hline & Group B & $0.031 \pm 0.012$ & $0.083 \pm 0.033$ & $0.054 \pm 0.039$ \\
\hline
\end{tabular}

* denotes $\mathrm{p}<0.05$ compared to baseline value. \# denotes $\mathrm{p}<0.05$ between groups

Alterations of mitochondria were observed at the end of ischemia and during reperfusion in both groups without any effect of H290/51. Ischemia increased the relative volume of cytosol within the cardiomyocytes ( $V_{v}$ cell edema/myocyte) in both groups, and this increase was significantly higher in hearts not pretreated with H290/51 (Table III). During reperfusion the volume fraction of cytosol normalized in both groups.

\section{Discussion}

Ischemia and reperfusion caused interstitial and cellular edema, disruption of sarcolemma, swollen mitochondria and myofilament disruption. These findings are in agreement with earlier studies $(12,15,28)$. Quantitative stereological morphometry suggested that the hearts treated with $\mathrm{H} 290 / 51$ had less injury than control hearts. After ischemia the increased interstitial volume and the increased volume fractions of both interstitium and myocytes was inhibited by H290/51. This demonstrates that both extraand intracellular edema after ischemia was inhibited or reduced by this drug. In addition the volume fraction capillary/myocardium was less in the control group at the end of ischemia. This may be explained by a relatively greater interstitial volume due to edema in the control group. In explaining volume fraction differences it should be noted, however, that volume fractions are given as ratios. An altered volume fraction may be due to an altered numerator or an altered reference volume. 
Surprisingly the differences between groups occurred at the end of ischemia, but no difference was found during reperfusion, although several changes compared to baseline was observed. One can speculate if some differences during reperfusion would have become apparent if the number of hearts had been increased or if the point(s) of time for evaluation had been different. On the basis of our data we can only state that in the present study no tendency towards any difference between groups is evident in the reperfusion period. Consequently, from a morphological and ultrastructural point of view H290/51 has anti-ischemic rather than anti-reperfusion effects. We have earlier reported that when H290/51 was given only during reperfusion, the functional and biochemical protection was less marked than when preischemic administration was applied (22). The interpretation was that H290/51, when given only during reperfusion, had not reached the intracellular sites of ROS generation and lipid peroxidation within the first 60 seconds. However, a direct anti-ischemic effect was not excluded (22). From the present work it appears that $\mathrm{H} 290 / 51$ indeed had anti-ischemic effects.

There has been much debate on whether reversibly injured myocytes, potentially viable at the time of reperfusion, die as a consequence of reperfusion (8). Experimental results are somewhat inconclusive, with studies supporting the existence of lethal reperfusion injury (6) but others failed to demonstrate this phenomenon $(30,36)$. Morphological studies also yielded inconsistent results. Some investigators could not demonstrate the extension of necrosis by reperfusion by electron microscopy (9) and attributed cell death predominantly to ischemia and not reperfusion (16). On the other hand, others published findings consistent with the occurrence of necrosis during reperfusion $(5,19,26)$. Opponents to reperfusion injury concept argue that the major part of myocardial injury occurs during ischemia, even if it may manifest itself both histologically and functionally only after reperfusion (24). Most investigators seem to agree, however, that reperfusion injury is a true entity. In the present study the morphologic alterations were surprisingly few, except for an increase of mitochondrial, interstitial, and the left ventricular volume indicating intra- and extracellular edema, with the ultrastructure becoming more normal during reperfusion. The increasing edema may be continuation of an ischemic injury and does per se suggest that reperfusion did take place.

A low concentration of ROS is measurable in vivo in the intact beating heart (10). During ischemia there is a threefold increase in ROS production, followed by a subsequent burst during reperfusion (37). In our experiments the majority of differences between groups that might be contributed to the effect of H290/51 were observable after ischemia, but less prominent after reperfusion. Possibly the present concentration of H290/51 was able to quench the ROS during ischemia, but was not capable to counteract the burst during reperfusion. However, at a concentration of $10^{-6} \mathrm{~mol} / \mathrm{l}(22)$ H290/51 reduced reoxygenation injury in cultured myocytes, and almost totally 
inhibited leakage of lactate dehydrogenase (22). This concentration was also used in the study where H290/51 did not give good protection when given only during reperfusion (22).

Ultrastructural changes of the mitochondria are a crucial step in the development of ROS-induced myocardial damage $(14,18)$. In our experiments H290/51 did not influence the appearance of mitochondria after ischemia. $V_{v}$ (alt mito/myocard) remained similar in both groups at the end of a 20-minute reperfusion. The absolute volume of mitochondria, however, was increased only in the group without H290/51, but only during reperfusion. The increase of $V_{v}$ mito/myocyte observed in the untreated group both after ischemia and reperfusion indicated that mitochondria were swollen above the extent of the general myocardial swelling in this group. Others (34) have reported results similar to our findings. In these experiments supplementation of superoxide dismutase and catalase to isolated rat hearts subjected to ischemiareperfusion resulted in better preserved sarcolemmal integrity. However, there were no effects detected on differences in mitochondrial swelling. Margination of nuclear chromatin occurred in a very low $(<0.7)$ percentage in both groups. A parallel effect was observed after reperfusion of dog skeletal muscle rendered ischemic (35). It is possible that in our experiments the protection afforded by H290/51 was similar, i.e. a protection on cellular membranes and sarcolemmal integrity, but less on mitochondria.

H290/51 was originally regarded as an inhibitor of lipid peroxidation. However, if it is more an anti-ischemic drug than an anti-reperfusion drug, then it may have other actions as well. Recent studies have shown that H290/51 inhibits upregulation of nNOS during heat stress (1), and in the same model it attenuates the upregulation of $72 \mathrm{kD}$ heat shock protein (13). These data really do indicate possible cardioprotective properties of $\mathrm{H} 290 / 51$ beyond inhibition of lipid peroxidaton only.

In conclusion, H290/51 provided protection against ultrastructural alterations in rat myocardium following ischemia. The effect exerted on mitochondrial ultrastructure was limited. There was a more pronounced effect seen in interstitial and cellular edema accumulation and cellular volume control. In the present experiments this compound provided better preserved sarcolemmal integrity during ischemia and this cytoprotective effect vanished after reperfusion.

\section{Acknowledgements}

This investigation was supported by grants from the Swedish Medical Research Council (11235 and 12665), The Swedish Heart-Lung Foundation, the Foundations Fredrik o Ingrid Thuring, Tore Nilsson, Åke Wiberg, The Laerdahl Foundation for Acute Medicine, Sigurd and Elsa Goljes Memory, and the Karolinska Institutet. H290/51 was provided by Pharmacology CV, AstraZeneca R \& D, Mölndal, Sweden as a gift.

A. Nagy was supported by a travel grant from Soros Foundation, Budapest, Hungary. 


\section{REFERENCES}

1. Alm P, Sharma HS, Sjöquist PO, Westman J: A new antioxidant compound H-290/51 attenuates nitric oxide synthase and heme oxygenase expression following hyperthermic brain injury. An experimental study using immunohistochemistry in the rat. Amino Acids 19, 383-394 (2000)

2. Ambrosio G, Tritto I: Reperfusion injury: experimental evidence and clinical implications. Am. Heart J. 138, S69-75 (1999)

3. Ambrosio G, Zweier JL, Duilio C, Kuppusamy P, Santoro G, Elia PP, Tritto I, Cirillo P, Condorelli M, Chiariello M: Evidence that mitochondrial respiration is a source of potentially toxic oxygen free radicals in intact rabbit hearts subjected to ischemia and reflow. J Biol. Chem. 268, 18532-18541 (1993)

4. Baddeley AJ, Gundersen HJ, Cruz-Orive LM: Estimation of surface area from vertical sections. J. Microsc. 142, 259-276 (1986)

5. Becker LC, Jeremy RW, Schaper J, Schaper W: Ultrastructural assessment of myocardial necrosis occurring during ischemia and 3-h reperfusion in the dog. Am. J. Physiol. 277, H243-252 (1999)

6. Bolli R: Causative role of oxyradicals in myocardial stunning: a proven hypothesis. Basic Res. Cardiol. 93, 156-162 (1998)

7. Dhalla NS, Elmoselhi AB, Hata T, Makino N: Status of myocardial antioxidants in ischemiareperfusion injury. Cardiovasc. Res. 47, 446-456 (2000)

8. Ferrari R, Hearse DJ: Reperfusion injury: Does it Exist and does it have clinical relevance? J. Thromb. Thrombolysis 4, 25-34 (1997)

9. Ganz W, Watanabe I, Kanamasa K, Yano J, Han DS, Fishbein MC: Does reperfusion extend necrosis? A study in a single territory of myocardial ischemia-half reperfused and half not reperfused. Circulation 82, 1020-1033 (1990)

10. Grill HP, Zweier JL, Kuppusamy P, Weisfeldt ML, Flaherty JT: Direct measurement of myocardial free radical generation in an in vivo model: effects of postischemic reperfusion and treatment with human recombinant superoxide dismutase. J. Am. Coll. Cardiol. 20, 1604-1611 (1992)

11. Hearse DJ, Humphrey SM, Nayler WG, Slade A, Border D: Ultrastructural damage associated with reoxygenation of the anoxic myocardium. J. Mol. Cell. Cardiol. 7, 315-324 (1975)

12. Hearse DJ: Myocardial protection during ischemia and reperfusion. Mol. Cell. Biochem. 186, 177-184 (1998)

13. Hedlund S, Sharma HS, Sjöquist PO, Westman J: A new antioxidant compound H-290/51 attenuates heat shock protein (HSP $72 \mathrm{kD}$ ) response, edema and cell injury following acute heat exposure. An experimental study using light and electron microscopy in the rat. Journal of Thermal Biology 24, 409-414 (1999)

14. Hegstad AC, Ytrehus K, Myklebust R, Jorgensen L: Ultrastructural changes in the myocardial myocytic mitochondria: crucial step in the development of oxygen radical-induced damage in isolated rat hearts? Basic Res. Cardiol. 89, 128-138 (1994)

15. Jennings RB, Ganote CE: Structural changes in myocardium during acute ischemia. Circ. Res. 35, 156-172 (1974)

16. Klein HH, Pich S, Lindert-Heimberg S, Nebendahl K, Sprengel U, Müller HH, Schaper J: Ultrastructural evaluation of postischemic cell death (lethal reperfusion injury) in porcine hearts. J. Thromb. Thrombolysis 3, 361-366 (1996)

17. Kloner RA, Bolli R, Marban E, Reinlib L, Braunwald E: Medical and cellular implications of stunning, hibernation, and preconditioning: an NHLBI workshop. Circulation 97, 1848-1867 (1998)

18. Lucas DT, Szweda LI: Cardiac reperfusion injury: aging, lipid peroxidation, and mitochondrial dysfunction. Proc. Natl. Acad. Sci. USA 95, 510-514 (1998)

19. Matsumura K, Jeremy RW, Schaper J, Becker LC: Progression of myocardial necrosis during reperfusion of ischemic myocardium. Circulation 97, 795-804 (1998) 
20. McDowel EM, Trump BF: Histologic fixatives suitable for diagnostic light and electron microscopy. Arch. Pathol. Lab. Med. 100, 405-414 (1976)

21. Nagy A, Sellei P, Valen G, Sjöquist PO, Vaage J: Effects of a novel low-molecular weight antioxidant on cardiac injury induced by hydrogen peroxide. Free Radic. Biol. Med. 20, 567-572 (1996)

22. Nagy A, Valen G, Ek B, Sellei P, Sjöquist PO, Vaage J: Effects of a novel, low-molecular weight inhibitor of lipid peroxidation on ischemia-reperfusion injury in isolated rat hearts and in cultured cardiomyocytes. Free Radic. Biol. Med. 24, 1462-1469 (1998)

23. Parinandi NL, Weis BK, Natarajan V, Schmid HH: Peroxidative modification of phospholipids in myocardial membranes. Arch. Biochem. Biophys. 280, 45-52 (1990)

24. Robicsek F, Schaper J: Reperfusion injury: fact or myth? J. Card. Surg. 12, 133-137 (1997)

25. Romaschin AD, Rebeyka I, Wilson GJ, Mickle DA: Conjugated dienes in ischemic and reperfused myocardium: an in vivo chemical signature of oxygen free radical mediated injury. J. Mol. Cell. Cardiol. 19, 289-302 (1987)

26. Röth E, Török B, Pollák Z, Temes G, Morvay G: Myocardial protection by antioxidant during permanent and temporary coronary occlusion in dogs. Basic Res. Cardiol. 82, 335-345 (1987)

27. Röth E: Oxygen free radicals and their clinical implications. Acta Chir. Hung. 36, 302-305 (1997)

28. Schaper J: Ultrastructural changes of the myocardium in regional ischaemia and infarction. European Heart Journal 7, Suppl B. 3-9 (1986)

29. Shimizu M, Wang QD, Sjöquist PO, Rydén L: Combination of a calcium antagonist, a lipidperoxidation inhibitor, and an angiotensin AT1-receptor antagonist provides additive myocardial infarct size-limiting effect in pigs. J. Cardiovasc. Pharmacol. 34, 512-517 (1999)

30. Tanaka M, Brooks SE, Richard VJ, FitzHarris GP, Stoler RC, Jennings RB, Arfors K.-E, Reimer KA: Effect of anti-CD-18 antibody on myocardial neutrophil accumulation and infarct size after ischemia and reperfusion in dogs. Circulation 87, 526-535 (1993)

31. Weibel ER, Bolender R (1973): Stereological techniques for electron microscopic morphometry. In: Principles and techniques for electron microscopy, eds. Hayat MA, Van Nostrand, New York, Vol. 3. pp. 237.

32. Westerlund C, Lindquist Ö, Sainsbury M, Schertzer HG, Sjöquist PO: Characterization of novel indenoindoles 1. Structure-activity relationships in different model systems of lipid peroxidation. Biochem. Pharmacol. 51, 1397-1402 (1996)

33. Wiklund L, Miller VM, McGregor CGA, Sjöquist PO, Berggren H, Nilsson F: Protective effects of an indenoindole antioxidant on coronary function after long-term storage. Transplantation 60, 774-778 (1995)

34. Ytrehus K, Gunnes S, Myklebust R, Mjøs O: Protection by superoxide dismutase and catalase in the isolated rat heart perfused after prolonged cardioplegia: a combined study of metabolic, functional, and morphometric ultrastructural variables. Cardiovasc. Res. 21, 492-499 (1987)

35. Ytrehus K, Reikeras O, Huseby N, Myklebust R: Ultrastructure of reperfused skeletal muscle: the effect of oxygen radical scavenger enzymes. Int. J. Microcirc. Clin. Exp. 15, 155-162 (1995)

36. Zahger D, Yano J, Chaux A, Fishbein MC, Ganz W: Absence of lethal reperfusion injury after 3 hours of reperfusion. A study in a single-canine-heart model of ischemia-reperfusion. Circulation 91, 2989-2994 (1995)

37. Zweier JL, Flaherty JT, Weisfeldt ML: Direct measurement of free radical generation following reperfusion of ischemic myocardium. Proc. Natl. Acad. Sci. USA 84, 1404-1407 (1987) 